\title{
Modelling of the ICF core sets for chronic ischemic heart disease using the LASSO model in Chinese patients
}

\author{
Meng You', Wen Fang ${ }^{2}$, Xu Wang $^{1}$ and Tiantong Yang ${ }^{1 *}$
}

\begin{abstract}
Background: This study aimed to examine the associations among the International Classification of Functioning, Disability, and Health (ICF) core sets relevant to chronic ischemic heart disease (CIHD) using the least absolute shrinkage and selection operator (LASSO) model based on the ICF core sets scale in Chinese patients.

Methods: This was a prospective study of 120 patients with CIHD selected from January 2013 to June 2014 at the Fada Institute of Forensic Medicine \& Science (Beijing, China). Functioning was qualified using the ICF core sets checklist for CIHD (Chinese version). The variables of core set categories of the ICF assessment scale for CIHD were entered into the LASSO model for mining dependencies among those variables. Graphical modeling was applied using LASSO generalized linear models.

Results: "Muscle endurance functions", "sensations associated with cardiovascular and respiratory functions", "blood vessel functions", and "heart functions" were the most injured in CIHD status. "Recreation and leisure" and "intimate relationships" were the most affected in CIHD status. "General social support services, systems, and policies" and "acquaintances, peers, colleagues, neighbors, and community members" were important for the outcome of functional status of the CIHD patient. "Economic self-sufficiency" and "family relationships" of the CIHD patient were not undermined in most cases.

Conclusions: Graphical modeling can be used to describe associations between different areas of functioning in CIHD patients. The results suggest that these associations could be used as basis to improve rehabilitation and provide a deeper understanding of functioning in Chinese CIHD patients.
\end{abstract}

Keywords: International classification of functioning, disability, and health, Least absolute shrinkage and selection operator model, Chronic ischemic heart disease, Functioning

\section{Background}

Chronic ischemic heart diseases (CIHD) encompass stable angina pectoris (or symptoms felt to be related to coronary artery disease (CAD), such as dyspnea), symptomatic CAD that became asymptomatic with appropriate treatments and regular follow-up, and newly symptomatic CAD deemed to already be in a chronic and stable condition [1]. Therefore, CIHD include heart conditions that exclude situations in which coronary artery thrombosis acutely dominates presentation [1]. CIHD is characterized

\footnotetext{
* Correspondence: yangtiantong@126.com

${ }^{1}$ Key Laboratory of Evidence Science (China University of Political Science and Law), Ministry of Education, Collaborative Innovation Center of Judicial Civilization, Beijing, China

Full list of author information is available at the end of the article
}

by episodes of unbalanced oxygen need/supply, leading to transient ischemia/hypoxia and symptoms of angina [2-4]. The prevalence of CIHD is 4-7\% in men aged 45-64 years and $12-14 \%$ in men aged $65-84$ years, compared to $5.7 \%$ in women aged $45-64$ years and $10-12 \%$ in women aged 65-84 years [5].

The estimated cardiac mortality in populations of patients with CIHD is $1.2-2.4 \%$ per year [6-8], but there is a wide variability among patients because of comorbidities such as hypertension and diabetes mellitus [1]. Assessing the prognosis is important because patients with a good prognosis could avoid unnecessary invasive tests and revascularization procedures [1].

(c) The Author(s). 2018 Open Access This article is distributed under the terms of the Creative Commons Attribution 4.0 International License (http://creativecommons.org/licenses/by/4.0/), which permits unrestricted use, distribution, and reproduction in any medium, provided you give appropriate credit to the original author(s) and the source, provide a link to the Creative Commons license, and indicate if changes were made. The Creative Commons Public Domain Dedication waiver (http://creativecommons.org/publicdomain/zero/1.0/) applies to the data made available in this article, unless otherwise stated. 
The International Classification of Functioning, Disability, and Health (ICF) is an international classification developed by the World Health Organization (WHO) $[9,10]$. In contrast to other international classifications, the ICF highlights the structure and measurement of "health components", and emphasizes on "functioning" rather than "impairment" to provide information on abnormal health status $[11,12]$. In order to ensure the wide application of ICF in clinical practice and studies measuring the health status of diseases, the WHO has developed the corresponding ICF core sets for evaluating the health status of some diseases, which refers to the selection of the fewest ICF categories relevant to the patient's function, disability, and health based on specific diseases and environments [13-15]. These core sets are a secure, fast, and accurate instrument for the application of ICF in clinical practice [16]. The ICF aims at providing a unified language for the description of health conditions in rehabilitation [17, 18]. Based on the ICF as a common language, it is possible to analyze functioning beyond the study of the incidence and prevalence of health conditions and beyond the limited aspects of functioning such as activities of daily living $[19,20]$.

With the ICF, it is possible to analyze the relationship of elements of functioning on the level of single categories. A promising approach to describe the complex relationships in human functioning is graphical modeling. The least absolute shrinkage and selection operator (LASSO) graphical model is a comprehensive probabilistic tool to analyze and visualize dependencies between random variables. The LASSO graphical model constricts a regression coefficient and thus, directly turns a portion of the coefficients with small absolute value to 0 $[21,22]$. The LASSO graphical model has the algorithmic computational complexity equal to that of the least square regression and is effective for selecting variables that have intense effects on dependent variables [23-25]. The correlations among these variables can be directly shown by functional topographic maps. Some authors have used graphical modeling to investigate ICF core sets. For example, Becker et al. [26] used graphical modeling to investigate the associations among functional categories of head and neck cancer in ICF. Kalisch et al. [27] used graphical models to investigate functional data in ICF and they believe that this method can become a tool for functional analysis. Similar to the above studies, Strobl et al. [28] used graphical modeling to study ICF and demonstrated "paths" related to "structures", which was a good illustration for the associations among ICF categories. Ehrmann et al. [29] used graphical modeling to describe and understand the functioning of people living with a health condition.

Nevertheless, no core sets specific to Chinese patients with CIHD are available. Since the ICF is an international and authoritative tool for functioning evaluation, the present study aimed to examine the associations among the ICF core sets relevant to CIHD using the LASSO model based on the ICF core sets scale in Chinese patients. An ICF theoretical structure-based CIHD functional topographic map was then created to provide evidence for CIHD-related impairment evaluation and give a deeper understanding of functioning in CIHD patients.

\section{Methods \\ Study design}

This was a prospective study of 120 patients with CIHD selected from January 2013 to June 2014 at the Fada Institute of Forensic Medicine \& Science (Beijing, China). The Fada Institute of Forensic Medicine \& Sciences is affiliated to the China University of Political Science and Law. It is also the national-level forensic expertise agency of China. In order to meet the needs of judicial trials and being entrusted by the court or insurance companies, this institution has to perform functional assessment for more than 3000 persons each year. Therefore, researchers in this institution should have the ability to perform objective and comprehensive assessment for functions of the human body. Patient data were reviewed by an accreditation agency, which fully disclosed medical condition of the patients to meet the requirements of comprehensiveness and sufficiency. Sample data involved in this study were all consecutive subjects that were cross-examined at the court. Medical records meeting the CIHD diagnostic criteria were included in the study.

In China, there is a lack of data for the misdiagnosis rate of chronic ischemic heart disease, but there are data about the misdiagnosis rate of acute myocardial infarction (AMI) (21.962\% from 2004 to 2013). Since chronic ischemic heart disease and AMI have common disease outcomes, we used the AMI misdiagnosis rate as estimation. Based on the formula:

$$
n=\frac{u_{\alpha}^{2} \sigma^{2}}{\delta^{2}}
$$

Power was set at 0.8 and $\beta$ at 0.2 . $u$ was the $Z$ score and $\alpha$ (two-sided) was set at 0.05 .

The overall misdiagnosis rate was $21.962 \% \times 0.2=4.3924 \%$. $\sigma$ was set at 21.962 and $\delta$ at 4 . The sample size was determined as 116 and a total of 120 subjects were included for the present analysis.

This study was approved by the ethics committee of the China Collaborative Innovation Center of Judicial Civilization (Beijing). Informed consent was obtained from all participants included in the study.

\section{Subjects}

The inclusion criteria were: 1) consistent with the diagnosis of angina (I20) or CIHD (I25) according to the 
International Classification of Diseases-10th Revision (ICD-10); 2) age $\geq 18$ years; and 3) no recent movement disorders or difficulties caused by surgeries, trauma, etc. Patients with difficulties in movement from recent surgery, trauma, or any other causes were excluded.

\section{Data acquisition}

Data in this study were all from lawsuits cases of personal injury claims or cases qualified with health insurance, including all medical records of patients that were approved by cross-examination at the court. These data can reflect the health conditions of the patients comprehensively. In this study, 16 experts were invited to evaluate qualifier scale of relevant categories based on medical data of patients and ICF CIHD checklist (Chinese version). If there were cases with unclear medical records, then data were supplemented by interview or professional observation.

The 16 clinical specialists were responsible for data collection; 12 were cardiovascular specialists and four were rehabilitation specialists. They received special training. They collected data from the 120 patients with CIHD using the ICF Core Sets checklist for CIHD (Chinese language version) [30]. In this checklist, a total of 46 categories are included under the four first categories (b. body functions, s. body structures, d. activities and participation, and e. environmental factors; Table 1). For body functions and structures, the level of impairment was assessed according to the ICF qualifier scale: 0 , no impairment; 1 , mild impairment; 2, moderate impairment; 3, severe impairment; and 4, complete impairment. For the environmental factor component: 0, no barriers; 1 , mild barriers; 2, moderate barriers; 3, severe barriers; and 4, complete barriers. For activities and participation: 0 , no difficulty; 1 , mild difficulty; 2, moderate difficulty; 3 , severe difficulty; and 4, complete difficulty. For all categories, not specified was encoded as 8 , and not applicable was encoded as 9.

\section{Data processing and interpretation}

The LASSO model was used to analyze the conditional dependence among the categorical variables of core sets for CIHD using MATLAB 8.3 (MathWorks, Natick, MA, USA) $[26,28]$. In the present model, there were 120 subjects and 46 ICF variables. The minimum mean square error (MMSE) and the coefficient vector were obtained by LASSO estimation; they were both considered as dependence coefficients.

The dependence coefficient showed the relative correlations among different categories. Analogical reasoning was applied to other variables to induce their corresponding variables.

\section{Results}

\section{Characteristics of the patients}

Among the 120 patients, there were 85 males and $35 \mathrm{fe}$ males, aged $35-82$ years. Based on the ICD-10, 79 cases were confirmed with angina (I20) and 41 with CIHD (I25). According to the New York Heart Association Functional Classification [31], 52 patients were class I, 37 were class II, 27 were class III, and four were class IV.

\section{Confinement degrees of the categories}

Individual scores are presented in the Additional file 1: Table S1. In this study, "out degree" stands for the frequency of appearance of a variable compared to others. The larger the frequency is, the more impact a variable has on other variables [32]. A direct weighted network diagram based on the dependence coefficients of different categories was plotted, and the relevant characteristics were analyzed. The maximum out degree of a node/category was 7 , while the minimum was 2 . The thicker the link was, the more heavily a node was weighted compared to others (Fig. 1). The out degrees of different categories are shown in Table 2. In the category of "body structures" (s), the out degree of 5410 was 4 , indicating that the "structures of the cardiovascular system" were involved in CIHD status. In the category of "body functions" (b), the out degrees of b740, b460, b415, and b410 were 6, indicating that the "muscle endurance functions", "sensations associated with cardiovascular and respiratory functions", "blood vessel functions", and "heart functions" were the most injured in CIHD status. In the category of "activities and participation" (d), the out degrees of d920 and d770 were 6 , indicating that "recreation and leisure" and "intimate relationships" were the most affected in CIHD status. In the category of "environmental factors" (e), the out degrees of e 575 and e325 were 7, indicating that "general social support services, systems, and policies" and "acquaintances, peers, colleagues, neighbors, and community members" were important for the outcome of functional status of the CIHD patient. Among all categories, the out degrees of $\mathrm{d} 870$ and $\mathrm{d} 760$ were the smallest, indicating that "economic self-sufficiency" and "family relationships" of the CIHD patient were not undermined in most cases. These results reveal that the main direction for CIHD status evaluation should be first determined, with major emphasis given to the category with the highest confinement degree.

\section{Relationship between two categories}

A total of 2116 dependence coefficients were acquired during the evaluation of the different categories of core sets for CIHD using ICF, including 14 dependence coefficients $>0.75$ and 16 dependence coefficients $<0.25$. The graphical model showed several complete bidirectional feedback loops in the core sets of CIHD categories based on different dependence coefficients (Tables 3 and 4).

Among all categories with dependence coefficients $>0.75$ (Table 3), d770 and d870 had the largest dependence coefficient (0.968), indicating that "intimate relationships" was 
Table 1 Short description of the ICF categories used for the graphs

\begin{tabular}{|c|c|c|c|c|c|c|c|}
\hline $\begin{array}{l}\overline{\text { ICF }} \\
\text { code }\end{array}$ & Category description & $\begin{array}{l}\text { ICF } \\
\text { code }\end{array}$ & Category description & $\begin{array}{l}\text { ICF } \\
\text { code }\end{array}$ & $\begin{array}{l}\text { Category } \\
\text { description }\end{array}$ & $\begin{array}{l}\text { ICF } \\
\text { code }\end{array}$ & Category description \\
\hline & $\begin{array}{l}\text { Chapter: structures of } \\
\text { the cardiovascular, } \\
\text { immunological, and } \\
\text { respiratory systems }\end{array}$ & & Chapter: mental functions & & $\begin{array}{l}\text { Chapter: general } \\
\text { tasks and } \\
\text { demands }\end{array}$ & & $\begin{array}{l}\text { Chapter: products and } \\
\text { technology }\end{array}$ \\
\hline s410 & $\begin{array}{l}\text { Structure of cardiovascular } \\
\text { system }\end{array}$ & b130 & Energy and drive functions & $d 230$ & $\begin{array}{l}\text { Carrying out daily } \\
\text { routine }\end{array}$ & e110 & $\begin{array}{l}\text { Products or substances for } \\
\text { personal consumption }\end{array}$ \\
\hline \multirow[t]{21}{*}{ s430 } & $\begin{array}{l}\text { Structure of respiratory } \\
\text { system }\end{array}$ & b134 & Sleep functions & $d 240$ & $\begin{array}{l}\text { Handling stress } \\
\text { and other } \\
\text { psychological } \\
\text { demands }\end{array}$ & e125 & $\begin{array}{l}\text { Products and technology for } \\
\text { communication }\end{array}$ \\
\hline & & b144 & Memory functions & & Chapter: mobility & & \\
\hline & & b152 & Emotional functions & $d 430$ & $\begin{array}{l}\text { Lifting and } \\
\text { carrying objects }\end{array}$ & e155 & $\begin{array}{l}\text { Design, construction and } \\
\text { building products and } \\
\text { technology of buildings } \\
\text { for private use }\end{array}$ \\
\hline & & & $\begin{array}{l}\text { Chapter: functions of the } \\
\text { cardiovascular, hematological, } \\
\text { immunological and respiratory } \\
\text { systems }\end{array}$ & $d 450$ & Walking & & $\begin{array}{l}\text { Chapter: natural environment } \\
\text { and human-made changes to } \\
\text { environment }\end{array}$ \\
\hline & & b410 & Heart functions & $d 455$ & Moving around & e225 & Climate \\
\hline & & b415 & Blood vessel functions & $d 460$ & $\begin{array}{l}\text { Moving around } \\
\text { in different } \\
\text { locations }\end{array}$ & e250 & Sound \\
\hline & & b420 & Blood pressure functions & & Chapter: self-care & e260 & Air quality \\
\hline & & b455 & Exercise tolerance functions & d570 & $\begin{array}{l}\text { Looking after } \\
\text { one's health }\end{array}$ & & $\begin{array}{l}\text { Chapter: support and } \\
\text { relationships }\end{array}$ \\
\hline & & b460 & $\begin{array}{l}\text { Sensations associated with } \\
\text { cardiovascular and respiratory } \\
\text { functions }\end{array}$ & & $\begin{array}{l}\text { Chapter: Domestic } \\
\text { life }\end{array}$ & e310 & Immediate family \\
\hline & & & $\begin{array}{l}\text { Chapter: functions of the } \\
\text { digestive, metabolic and } \\
\text { endocrine systems }\end{array}$ & $d 620$ & $\begin{array}{l}\text { Acquisition of } \\
\text { goods and } \\
\text { services }\end{array}$ & e315 & Extended family \\
\hline & & b530 & Weight maintenance functions & $d 630$ & Preparing meals & e320 & Friends \\
\hline & & & $\begin{array}{l}\text { Chapter: neuromusculoskeletal } \\
\text { and movement-related functions }\end{array}$ & $d 640$ & $\begin{array}{l}\text { Doing } \\
\text { housework }\end{array}$ & e325 & $\begin{array}{l}\text { Acquaintances, peers, } \\
\text { colleagues, neighbors, } \\
\text { and community members }\end{array}$ \\
\hline & & b730 & Muscle power functions & & $\begin{array}{l}\text { Chapter: } \\
\text { interpersonal } \\
\text { interactions and } \\
\text { relationships }\end{array}$ & e330 & $\begin{array}{l}\text { People in positions of } \\
\text { authority }\end{array}$ \\
\hline & & b740 & Muscle endurance functions & $d 760$ & $\begin{array}{l}\text { Family } \\
\text { relationships }\end{array}$ & e355 & Health professionals \\
\hline & & & & $d 770$ & $\begin{array}{l}\text { Intimate } \\
\text { relationships }\end{array}$ & & Chapter: attitudes \\
\hline & & & & & $\begin{array}{l}\text { Chapter: major } \\
\text { life areas }\end{array}$ & e410 & $\begin{array}{l}\text { Individual attitudes of } \\
\text { immediate family members }\end{array}$ \\
\hline & & & & d850 & $\begin{array}{l}\text { Remunerative } \\
\text { employment }\end{array}$ & e450 & $\begin{array}{l}\text { Individual attitudes of health } \\
\text { professionals }\end{array}$ \\
\hline & & & & $\mathrm{d} 870$ & $\begin{array}{l}\text { Economic self- } \\
\text { sufficiency }\end{array}$ & & $\begin{array}{l}\text { Chapter: services, systems and } \\
\text { policies }\end{array}$ \\
\hline & & & & & $\begin{array}{l}\text { Chapter: } \\
\text { community, social } \\
\text { and civic life }\end{array}$ & e570 & $\begin{array}{l}\text { Social security services, } \\
\text { systems and policies }\end{array}$ \\
\hline & & & & d920 & $\begin{array}{l}\text { Recreation and } \\
\text { leisure }\end{array}$ & e575 & $\begin{array}{l}\text { General social support services, } \\
\text { systems and policies }\end{array}$ \\
\hline & & & & & & e580 & $\begin{array}{l}\text { Health services, systems and } \\
\text { policies }\end{array}$ \\
\hline
\end{tabular}

closely correlated to "economic self-sufficiency"; the dependence coefficient for b130 and d450 was 0.916, indicating that "energy and drive functions" was closely correlated with "walking"; d460 and d240, b152 and b144, and d920 and $\mathrm{d} 430$ had dependence coefficients of $0.869,0.862$, and
0.86, respectively, indicating strong correlations between these categories in CIHD status, and the confinement of one category affects the other. Among the categories with dependence coefficient $<0.25$ (Table 4), e155 and d920 had dependence coefficients of -0.197 , showing a negative 


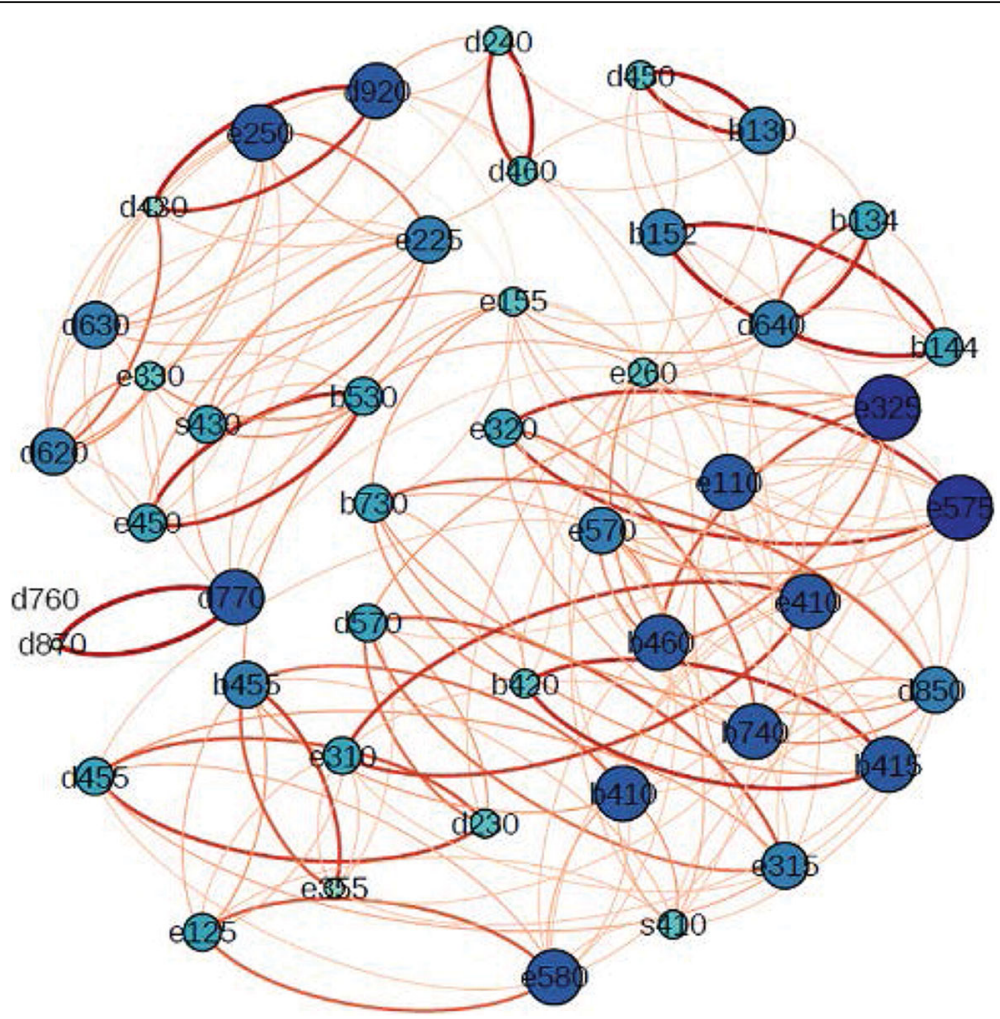

Fig. 1 Interaction diagram of classification of ICF core set related to CIHD. Thicker links indicate more heavy a node weigh in relations to others

Table 2 Out degree of classification core set node related to CIHD

\begin{tabular}{|c|c|c|c|c|c|c|c|}
\hline ICF code & Out degree & ICF code & Out degree & ICF code & Out degree & ICF code & Out degree \\
\hline$s 410$ & 4 & b740 & 6 & d920 & 6 & e575 & 7 \\
\hline \multirow[t]{16}{*}{ s430 } & 3 & b460 & 6 & d770 & 6 & e325 & 7 \\
\hline & & b415 & 6 & d850 & 5 & e580 & 6 \\
\hline & & b410 & 6 & $d 640$ & 5 & e410 & 6 \\
\hline & & b455 & 5 & d630 & 5 & e250 & 6 \\
\hline & & b152 & 5 & $d 620$ & 5 & e110 & 6 \\
\hline & & b130 & 5 & d570 & 4 & e570 & 5 \\
\hline & & b730 & 4 & $d 455$ & 4 & e315 & 5 \\
\hline & & b530 & 4 & $d 460$ & 3 & e225 & 5 \\
\hline & & b144 & 4 & $\mathrm{~d} 450$ & 3 & e450 & 4 \\
\hline & & b134 & 4 & $\mathrm{~d} 240$ & 3 & e320 & 4 \\
\hline & & b420 & 3 & $\mathrm{~d} 230$ & 3 & e310 & 4 \\
\hline & & & & $d 430$ & 2 & e125 & 4 \\
\hline & & & & d870 & 1 & e330 & 3 \\
\hline & & & & $d 760$ & 0 & e260 & 3 \\
\hline & & & & & & e155 & 3 \\
\hline & & & & & & e355 & 2 \\
\hline
\end{tabular}


Table 3 Dependence coefficient of classification related to CIHD core set (dependence coefficient $\geq 0.75$ )

\begin{tabular}{|c|c|c|c|c|c|c|c|c|c|c|c|c|c|c|}
\hline Category & $d 770$ & $\mathrm{~d} 870$ & b530 & e450 & d920 & $\mathrm{d} 240$ & $d 460$ & b130 & $d 450$ & b152 & b144 & $d 640$ & b415 & $\mathrm{b} 420$ \\
\hline b130 & 0 & 0 & 0 & 0 & 0 & 0.002 & 0.072 & 0 & 0.858 & 0 & 0 & 0 & 0 & 0 \\
\hline b134 & 0 & 0 & 0 & 0 & 0 & 0 & 0 & 0 & 0 & 0 & 0.081 & 0.779 & 0 & 0 \\
\hline b144 & 0 & 0 & 0 & 0 & 0 & 0 & 0 & 0 & 0 & 0.862 & 0 & 0.11 & 0 & 0 \\
\hline b152 & 0 & 0 & 0 & 0 & 0 & 0 & 0 & 0 & 0.024 & 0 & 0.857 & 0 & 0 & 0 \\
\hline b415 & 0 & 0 & 0 & 0 & 0 & 0 & 0 & 0 & 0 & 0 & 0 & 0.026 & 0 & 0.758 \\
\hline b420 & 0 & 0 & 0 & 0 & 0 & 0 & 0 & 0 & 0 & 0 & 0 & 0.015 & 0.773 & 0 \\
\hline b530 & 0 & 0 & 0 & 0.755 & 0 & 0 & 0 & 0 & 0 & 0 & 0 & 0 & 0 & 0 \\
\hline$d 240$ & 0 & 0 & 0 & 0 & 0.056 & 0 & 0.869 & 0 & 0 & 0 & 0 & 0 & 0 & 0 \\
\hline $\mathrm{d} 430$ & 0 & 0 & 0 & 0 & 0.86 & 0 & 0 & 0 & 0 & 0 & 0 & 0 & 0 & 0 \\
\hline$d 450$ & 0 & 0 & 0 & 0 & 0 & 0 & 0 & 0.916 & 0 & 0.09 & 0 & 0.017 & 0 & 0 \\
\hline$d 460$ & 0 & 0 & 0 & 0 & 0 & 0.778 & 0 & 0.03 & 0 & 0 & 0 & 0 & 0 & 0 \\
\hline d770 & 0 & 0.968 & 0 & 0 & 0 & 0 & 0 & 0 & 0 & 0 & 0 & 0 & 0 & 0 \\
\hline $\mathrm{d} 870$ & 0.968 & 0 & 0 & 0 & 0 & 0 & 0 & 0 & 0 & 0 & 0 & 0 & 0 & 0 \\
\hline e450 & 0 & 0 & 0.816 & 0 & 0 & 0 & 0 & 0 & 0 & 0 & 0 & 0 & 0 & 0 \\
\hline
\end{tabular}

Table 4 Dependence coefficient of classification related to CIHD core set (dependence coefficient $\leq 0.25$ )

\begin{tabular}{|c|c|c|c|c|c|c|c|c|c|c|c|c|c|c|c|c|}
\hline Category & s430 & e330 & b620 & e250 & d630 & b730 & b740 & e570 & e260 & b460 & e225 & $\mathrm{d} 570$ & b410 & e155 & $\mathrm{e} 110$ & s410 \\
\hline s410 & 0 & 0 & 0 & 0 & 0 & 0 & 0 & 0.128 & 0 & 0 & 0 & 0 & 0.150 & 0 & 0 & 0 \\
\hline b134 & 0 & 0 & 0 & 0 & 0 & 0 & 0 & 0 & 0.041 & 0 & 0 & 0 & 0 & 0.046 & 0 & 0 \\
\hline b144 & 0 & 0 & 0 & 0 & 0 & 0 & 0 & 0 & 0.231 & 0 & 0 & 0 & 0 & 0 & 0 & 0 \\
\hline b152 & 0 & 0 & 0 & 0 & 0 & 0 & 0 & 0 & 0.005 & 0 & 0 & 0 & 0 & 0 & 0 & 0.020 \\
\hline b740 & 0 & 0 & 0 & 0 & 0 & 0 & 0 & 0.011 & -0.040 & 0 & 0 & 0 & 0 & -0.021 & 0 & 0 \\
\hline$d 240$ & 0 & 0 & 0 & 0 & 0.094 & 0 & 0 & 0 & 0 & 0 & 0 & 0 & 0 & 0 & 0 & 0 \\
\hline$d 450$ & 0 & 0 & 0 & 0 & 0 & 0 & 0 & 0 & 0 & 0 & 0 & 0 & 0 & 0 & 0 & 0 \\
\hline$d 455$ & 0 & 0 & 0 & 0 & 0 & 0 & 0 & 0.048 & 0 & 0 & 0 & 0 & 0 & 0 & 0 & 0 \\
\hline$d 460$ & 0 & 0 & 0 & 0 & 0 & 0 & 0 & 0 & 0 & 0 & 0 & 0 & 0 & 0 & 0 & 0 \\
\hline d570 & 0 & 0 & 0 & 0 & 0 & 0 & 0 & 0 & 0 & 0 & 0 & 0 & 0 & 0 & 0 & 0 \\
\hline$d 630$ & 0 & 0 & 0.058 & 0.047 & 0 & 0 & 0 & 0 & 0 & 0 & 0.042 & 0 & 0 & 0 & 0 & 0 \\
\hline$d 760$ & 0 & 0 & 0 & 0 & 0 & 0 & 0 & 0 & 0 & 0 & 0 & 0 & 0 & 0 & 0 & 0 \\
\hline d770 & 0.208 & 0.046 & 0 & 0 & 0 & 0 & 0 & 0 & -0.052 & 0 & 0.067 & 0 & 0 & 0.078 & 0 & 0 \\
\hline $\mathrm{d} 870$ & 0 & 0 & 0 & 0 & 0 & 0 & 0 & 0 & 0 & 0 & 0 & 0 & 0 & 0 & 0 & 0 \\
\hline$d 920$ & 0 & 0 & 0 & 0 & 0.235 & 0 & 0 & 0 & -0.095 & 0 & 0 & 0 & 0 & -0.197 & 0.045 & 0 \\
\hline e110 & 0 & 0 & 0 & 0 & 0 & 0 & 0 & 0 & 0 & 0 & 0 & 0 & 0 & 0.141 & 0 & 0 \\
\hline e125 & 0 & 0 & 0 & 0 & 0 & 0 & 0 & 0 & 0 & 0 & 0 & 0 & 0 & 0 & 0 & 0.064 \\
\hline e155 & 0 & 0 & 0 & 0 & 0 & 0.021 & 0 & 0 & 0.014 & 0 & 0 & 0 & 0 & 0 & 0.012 & 0 \\
\hline e260 & 0 & 0 & 0 & 0 & 0 & 0 & 0 & 0.027 & 0 & 0.029 & 0 & 0 & 0 & 0 & 0 & 0 \\
\hline e310 & 0 & 0 & 0 & 0 & 0 & 0 & 0.014 & 0 & 0 & 0 & 0 & 0 & 0 & 0 & 0 & 0 \\
\hline e355 & 0 & 0 & 0 & 0 & 0 & 0 & 0 & 0 & 0 & 0 & 0 & 0 & 0 & 0 & 0 & 0 \\
\hline e450 & 0 & 0 & 0.016 & 0 & 0.021 & 0 & 0 & 0 & 0 & 0 & 0.240 & 0 & 0 & 0 & 0 & 0 \\
\hline e580 & 0 & 0 & 0 & 0 & 0 & 0 & 0 & 0 & 0 & 0.073 & 0 & 0 & 0.206 & 0 & 0 & 0.010 \\
\hline
\end{tabular}


correlation, indicating that "recreation and leisure" was not confined but enhanced although "design, construction, and building products and technology of buildings for private use" was confined; the dependence coefficients between e260 and d920/d770 were -0.095 and - 0.052, indicating that "recreation and leisure" and "intimate relationships" were enhanced even though "air quality" was confined. The categories showing either positive or negative correlations indicated that the correlations among different confined categories should be studied when evaluating CIHD-related status so as to determine the interactions among different categories and comprehensively evaluate the confined functioning status.

\section{Correlations among multiple categories}

Correlations existed among multiple categories of ICF core sets for CIHD. The dependence coefficients for b134, d640, d450, b152, and b144 linked to b134 were $0.779,0.059,0.090,0.857$, and 0.228 , respectively; if the above category order was reversed, the dependence coefficients were $0.857,0.862,0.024,0.017$, and 0.652 , respectively, indicating that "sleep functions" was correlated with "doing housework", "walking", "emotional function", and "memory functions" and thus, a complete bidirectional feedback loops existed. This also suggested that the aforementioned categories can be confined in CIHD status, and the confinement degree was affected by other categories of the same feedback loop, indicating that a holistic approach is required for evaluating CIHD status, and to clarify the essential pathophysiological mechanisms and prognostic rules of functioning confinement for the CIHD patient with respect to correlation among multiple confined components.

\section{Discussion}

LASSO is a method of compressive estimation proposed by Tibshirani in 1996 and is suitable for managing multicollinearity problems [33]. It is a regression method that can simultaneously perform parameter estimation and implement variable selection. Compared to other models, a graphical model can represent the dependence of the probability of variables using graphics, as well as represent joint probability distribution of variables associated with the model. It provides a simple way to visualize the structure of probabilistic model. By observing the graph, readers can understand the nature of the model more deeply. Induction of advanced model and complex calculations in the machine learning process can be expressed based on graphical calculation. The graphs implicitly carry the underlying mathematical expressions. Some authors have used graphical modeling to investigate ICF core sets [26-29]. The associations and degree of association were intuitively displayed by graphs, which can be a reference for diagnosis, functional limitation, functional assessment, comprehensive treatment and rehabilitation involved in chronic ischemic heart disease.

As an international standard for describing function and health, the ICF supplements abundant health status information on individuals' and population's "functioning", and demonstrates different functioning levels between disease occurrence and lesion outcome [34]. ICF is increasingly used for the evaluation of disease and lesion outcome in clinical practice and research [35]. This study aimed to examine the associations among the ICF core sets relevant to CIHD using the LASSO model based on the ICF core sets scale in Chinese patients. The results showed that "muscle endurance functions", "sensations associated with cardiovascular and respiratory functions", "blood vessel functions", and "heart functions" were the most injured in CIHD. "Recreation and leisure" and "intimate relationships" were the most affected in CIHD status. "General social support services, systems, and policies" and "acquaintances, peers, colleagues, neighbors, and community members" were important for the outcome of functional status of the CIHD patient. "Economic self-sufficiency" and "family relationships" of the CIHD patient were not undermined in most cases. Therefore, graphical modeling can be used to describe associations between different areas of functioning in CIHD patients. The results suggest that these associations could be used as basis to improve rehabilitation and provide a deeper understanding of functioning in Chinese CIHD patients.

ICF is a new classification system for health components based on interaction patterns. Individual functions of specific fields result from the interactions and complex correlations between health status and background factors (including environmental and individual factors). The "function", "health", and "disability" are independent and correlated, and they integrate health status, function, impairment, and background factors into a bidirectional interactive unified system [36, 37]. Therefore, ICF is a commonly used instrument that provides a unified and standard system for the description of health and health-related status worldwide [38]. Using the LASSO algorithm for the mathematical modeling of sample data and drawing a topographic diagram of correlations among ICF core sets for CIHD helps analyze the confinement degrees among body structures, functions, and activity participation, as well as their interactions in CIHD. It also provides robust scientific evidence for the introduction of ICF in functional recovery and disability evaluation, and improvement of the influence and recognition of evaluation results.

A previous study in patients with head and neck cancer showed that graphical modeling could be used to describe the associations among areas of functioning in these patients, providing a better basis for the management of these patients [26]. Another study in patients with traumatic brain injury (TBI) showed that the LASSO model 
could be used to construct high-order functional networks for application in clinical settings [22]. Nevertheless, compared with the former ICF core classification sets of TBI [22], the number of classifications was higher in the present study and their complexity was also higher. For the first time, a negative correlation was underlined.

In the present study, "muscle endurance functions", "sensations associated with cardiovascular and respiratory functions", "blood vessel functions", and "heart functions" were the most injured in CIHD. "Recreation and leisure" and "intimate relationships" were the most affected in CIHD. These results are in line with previous studies of ICF in patients with heart diseases $[30,39,40]$ and consistent with the course of the disease. "General social support services, systems, and policies" and "acquaintances, peers, colleagues, neighbors, and community members" are important for the outcome of functional status of the CIHD patient, as supported by a number of studies [41-43].

The results of the limited extent of category suggest that during CIHD-related disability assessment, the direction of the assessment should be clarified, focusing on the evaluation of the restricted categories that are more likely to be affected according to the out-degree of different classifications, and reasonable arrangement of the assessment sequence. Since there are positive and negative correlations among the classifications, the assessment should focus on the connection between two restricted categories to determine the degree of mutual influence among various categories, thus comprehensively and accurately evaluate the status of limited function of patients with CIHD during the evaluation of their disability.

The associations among multiple categories imply that there is a restricted situation in the above-mentioned classifications in the CIHD state, and the degree of restriction is related to the other categories in the feedback loop. This suggests that we should have the holistic concept in disability assessment, and recognize the fundamental pathophysiological process and outcome of the limited function of CIHD from the perspective of interdependencies of multiple restricted components.

The limitations of the present study are that the score data obtained by the interviews were subjective. In addition, it is still difficult to introduce the ICF standard in the current Chinese health care system. The LASSO approach itself has some limitations such as the consideration of only a small number of possible graphs [44], also as the dynamic changes in the relations among factors [45, 46]. Finally, 16 specialists visited the patients, which could introduce some bias. Additional studies are still necessary to refine the model.

\section{Conclusions}

In conclusion, graphical modeling can be used to describe associations between different areas of functioning in CIHD patients. The results suggest that these associations could be used as basis to improve rehabilitation and provide a deeper understanding of functioning in Chinese CIHD patients.

\section{Additional file}

Additional file 1: Table S1. Scores for each individual item of the ICF core sets. (DOCX $14 \mathrm{~kb})$

\begin{abstract}
Abbreviations
CAD: Coronary artery disease; CIHD: Chronic ischemic heart disease; ICF: International Classification of Functioning, Disability, and Health; LASSO: Least absolute shrinkage and selection operator; MMSE: Minimum mean square error; TBI: Traumatic brain injury; WHO: World Health Organization

\section{Acknowledgement}

This study was supported by Double First-Class" University Project and Innovative Talents Training Project(2011-051040), Program for Young Innovative Research Team in China University of Political Science and Law(16CXTD05)and Program for Young Innovative Research Team in China University of Political Science and Law(18CXTD09).
\end{abstract}

Availability of data and materials

All data generated or analyzed during this study are included in this article.

Authors' contributions

MY conceived and coordinated the study, designed, performed and analyzed the experiments, wrote the paper. WF, XW and TY carried out the data collection, data analysis, and revised the paper. All authors reviewed the results and approved the final version of the manuscript.

Ethics approval and consent to participate

This study was approved by the ethics committee of the China Collaborative Innovation Center of Judicial Civilization (Beijing). Informed consent was obtained from all individual participants included in the study.

Consent for publication

Informed consent was obtained from all individual participants included in the study.

\section{Competing interests}

The authors declare that they have no competing interests.

\section{Publisher's Note}

Springer Nature remains neutral with regard to jurisdictional claims in published maps and institutional affiliations.

\section{Author details}

${ }^{1}$ Key Laboratory of Evidence Science (China University of Political Science and Law), Ministry of Education, Collaborative Innovation Center of Judicial Civilization, Beijing, China. ${ }^{2}$ Beijing Jiaotong University, Beijing, China.

Received: 11 July 2017 Accepted: 13 June 2018

Published online: 11 July 2018

\section{References}

1. Task Force M, Montalescot G, Sechtem U, Achenbach S, Andreotti F, Arden C, et al. 2013 ESC guidelines on the management of stable coronary artery disease: the task force on the management of stable coronary artery disease of the European Society of Cardiology. Eur Heart J. 2013;34:2949-3003.

2. Fox K, Garcia MA, Ardissino D, Buszman P, Camici PG, Crea F, et al. Guidelines on the management of stable angina pectoris: executive summary: the task force on the management of stable angina pectoris of the European Society of Cardiology. Eur Heart J. 2006;27:1341-81.

3. Gibbons RJ, Chatterjee K, Daley J, Douglas JS, Fihn SD, Gardin JM, et al. ACC/ AHAVACP-ASIM guidelines for the management of patients with chronic stable angina: a report of the American College of Cardiology/American Heart Association task force on practice guidelines (committee on Management of Patients with Chronic Stable Angina). J Am Coll Cardiol. 1999;33:2092-197. 
4. Campeau L. The Canadian cardiovascular society grading of angina pectoris revisited 30 years later. Can J Cardiol. 2002;18:371-9.

5. National Institutes of Health. National Heart, Lung, and Blood Institute. Morbidity \& Mortality: 2012 Chart book on cardiovascular, lung, and blood diseases. Bethesda: National Institutes of Health; 2012.

6. Chung SC, Hlatky MA, Faxon D, Ramanathan K, Adler D, Mooradian A, et al. The effect of age on clinical outcomes and health status BARI 2D (bypass angioplasty revascularization investigation in type 2 diabetes). J Am Coll Cardiol. 2011;58:810-9.

7. Group BDS, Frye RL, August P, Brooks MM, Hardison RM, Kelsey SF, et al. A randomized trial of therapies for type 2 diabetes and coronary artery disease. N Engl J Med. 2009;360:2503-15.

8. Steg PG, Greenlaw N, Tardif JC, Tendera M, Ford I, Kaab S, et al. Women and men with stable coronary artery disease have similar clinical outcomes: insights from the international prospective CLARIFY registry. Eur Heart J. 2012;33:2831-40

9. Dahl TH. International classification of functioning, disability and health: an introduction and discussion of its potential impact on rehabilitation services and research. J Rehabil Med. 2002:34:201-4.

10. de Kleijn-de Vrankrijker MW. The long way from the international classification of impairments, disabilities and handicaps (ICIDH) to the international classification of functioning, disability and health (ICF). Disabil Rehabil. 2003;25:561-4.

11. Cieza A, Brockow T, Ewert T, Amman E, Kollerits B, Chatterji S, et al. Linking health-status measurements to the international classification of functioning, disability and health. J Rehabil Med. 2002;34:205-10.

12. Ustun TB, Chatterji S, Bickenbach J, Kostanjsek N, Schneider M. The international classification of functioning, disability and health: a new tool for understanding disability and health. Disabil Rehabil. 2003;25:565-71.

13. Cieza A, Geyh S, Chatterji S, Kostanjsek N, Ustun BT, Stucki G. Identification of candidate categories of the International Classification of Functioning Disability and Health (ICF) for a Generic ICF Core Set based on regression modelling. BMC Med Res Methodol. 2006;6:36.

14. Jerosch-Herold C, Leite JC, Song F. A systematic review of outcomes assessed in randomized controlled trials of surgical interventions for carpal tunnel syndrome using the International Classification of Functioning, Disability and Health (ICF) as a reference tool. BMC Musculoskelet Disord. 2006;7:96.

15. Maini M. Application problems of the use of the Core set ICF in the rehabilitation area. G Ital Med Lav Ergon. 2008;30:178-84.

16. Ruaro JA, Ruaro MB, Guerra RO. International classification of functioning, disability and health core set for physical health of older adults. J Geriatr Phys Ther. 2014;37:147-53.

17. Raggi A, Leonardi M, Covelli V, Sattin D, Scaratti C, Schiavolin S, et al. The ICF as a framework to collect and interpret data on the extent and variety of disability in neurological conditions. NeuroRehabilitation. 2015;36:17-22.

18. Johnston M, Dixon D. Developing an integrated biomedical and behavioural theory of functioning and disability: adding models of behaviour to the ICF framework. Health Psychol Rev. 2014;8:381-403.

19. Grawburg M, Howe T, Worrall L, Scarinci N. Describing the impact of aphasia on close family members using the ICF framework. Disabil Rehabil. 2014;36:1184-95.

20. Kohler F, Connolly C, Sakaria A, Stendara K, Buhagiar M, Mojaddidi M. Can the ICF be used as a rehabilitation outcome measure? A study looking at the inter- and intra-rater reliability of ICF categories derived from an ADL assessment tool. J Rehabil Med. 2013:45:881-7.

21. Strobl R, Grill E, Mansmann U. Graphical modeling of binary data using the LASSO: a simulation study. BMC Med Res Methodol. 2012;12:16.

22. Zhu D, Li X, Jiang X, Chen H, Shen D, Liu T. Exploring high-order functional interactions via structurally-weighted LASSO models. Inf Process Med Imaging. 2013;23:13-24.

23. Mazumder R, Hastie T. Exact covariance thresholding into connected components for large-scale graphical lasso. J Mach Learn Res. 2012;13:781-94.

24. Zhao Y, Ogden RT, Reiss PT. Wavelet-based LASSO in functional linear regression. J Comput Graph Stat. 2012;21:600-17.

25. Li B, Chuns H, Zhao H. Sparse estimation of conditional graphical models with application to gene networks. J Am Stat Assoc. 2012;107:152-67.

26. Becker S, Strobl R, Cieza A, Grill E, Harreus U, Tschiesner U. Graphical modeling can be used to illustrate associations between variables describing functioning in head and neck cancer patients. J Clin Epidemiol. 2011;64:885-92.

27. Kalisch M, Fellinghauer BA, Grill E, Maathuis MH, Mansmann U, Buhlmann P, et al. Understanding human functioning using graphical models. BMC Med Res Methodol. 2010;10:14.

28. Strobl R, Stucki G, Grill E, Muller M, Mansmann U. Graphical models illustrated complex associations between variables describing human functioning. J Clin Epidemiol. 2009;62:922-33.
29. Ehrmann C, Bickenbach J, Stucki G. Graphical modeling: a tool for describing and understanding the functioning of people living with a health condition. Eur J Phys Rehabil Med. 2017;53.

30. Boldt C, Grill E, Wildner M, Portenier L, Wilke S, Stucki G, et al. ICF Core set for patients with cardiopulmonary conditions in the acute hospital. Disabil Rehabil. 2005;27:375-80.

31. Apostolakis E, Akinosoglou K. Reexamining the New York heart association functional classification of heart failure. Am J Cardiol. 2007;100:911-2.

32. Williams O, Del Genio Cl. Degree correlations in directed scale-free networks. PLoS One. 2014;9:e110121.

33. Tibshirani R. The lasso method for variable selection in the cox model. Stat Med. 1997;16:385-95.

34. Alford VM, Remedios $L$, Webb GR, Ewen $\mathrm{S}$. The use of the international classification of functioning, disability and health (ICF) in indigenous healthcare: a systematic literature review. Int J Equity Health. 2013;12:32.

35. Kostanjsek N. Use of the international classification of functioning, disability and health (ICF) as a conceptual framework and common language for disability statistics and health information systems. BMC Public Health. 2011; 11(Suppl 4):S3.

36. Marfeo EE, Haley SM, Jette AM, Eisen SV, Ni P, Bogusz K, et al. Conceptual foundation for measures of physical function and behavioral health function for social security work disability evaluation. Arch Phys Med Rehabil. 2013; 94:1645-52. e2

37. Noonan VK, Kopec JA, Noreau L, Singer J, Chan A, Masse LC, et al. Comparing the content of participation instruments using the international classification of functioning, disability and health. Health Qual Life Outcomes. 2009;7:93.

38. Anner J, Schwegler U, Kunz R, Trezzini B, de Boer W. Evaluation of work disability and the international classification of functioning, disability and health: what to expect and what not. BMC Public Health. 2012;12:470.

39. Cieza A, Stucki A, Geyh S, Berteanu M, Quittan M, Simon A, et al. ICF Core sets for chronic ischaemic heart disease. J Rehabil Med. 2004:36:94-9.

40. Racca V, Di Rienzo M, Mazzini P, Ripamonti V, Gasti G, Spezzaferri R, et al. ICF-based approach to evaluating functionality in cardiac rehabilitation patients after heart surgery. Eur J Phys Rehabil Med. 2015:51:457-68.

41. Vogt TM, Mullooly JP, Ernst D, Pope CR, Hollis JF. Social networks as predictors of ischemic heart disease, cancer, stroke and hypertension: incidence, survival and mortality. J Clin Epidemiol. 1992;45:659-66.

42. Barefoot JC, Gronbaek M, Jensen G, Schnohr P, Prescott E. Social network diversity and risks of ischemic heart disease and total mortality: findings from the Copenhagen City heart study. Am J Epidemiol. 2005;161:960-7.

43. Valtorta NK, Kanaan M, Gilbody S, Ronzi S, Hanratty B. Loneliness and social isolation as risk factors for coronary heart disease and stroke: systematic review and meta-analysis of longitudinal observational studies. Heart. 2016; 102:1009-16.

44. Neapolitan RE. Learning Bayesian networks. New Jersey: Prentice Hall; 2004.

45. Chang C, Glover GH. Time-frequency dynamics of resting-state brain connectivity measured with fMRI. Neurolmage. 2010;50:81-98.

46. Majeed W, Magnuson M, Hasenkamp W, Schwarb H, Schumacher EH, Barsalou $L$, et al. Spatiotemporal dynamics of low frequency BOLD fluctuations in rats and humans. Neurolmage. 2011;54:1140-50.

\section{Ready to submit your research? Choose BMC and benefit from:}

- fast, convenient online submission

- thorough peer review by experienced researchers in your field

- rapid publication on acceptance

- support for research data, including large and complex data types

- gold Open Access which fosters wider collaboration and increased citations

- maximum visibility for your research: over $100 \mathrm{M}$ website views per year

At BMC, research is always in progress.

Learn more biomedcentral.com/submissions 